\title{
Pressure-Arching Characteristics in Roof Blocks during Shallow Coal Mining
}

\author{
Yanhai Zhao, ${ }^{1}$ Shuren Wang $\mathbb{D}^{1,2}$ Paul Hagan ${ }^{1 D},{ }^{2}$ Lianwei Ren, ${ }^{1}$ and Zhengsheng Zou ${ }^{1}$ \\ ${ }^{1}$ International Joint Research Laboratory of Henan Province for Underground Space Development and Disaster Prevention, \\ Henan Polytechnic University, Jiaozuo 454003, China \\ ${ }^{2}$ School of Mining Engineering, University of New South Wales, Sydney, NSW 2052, Australia
}

Correspondence should be addressed to Shuren Wang; w_sr88@163.com

Received 2 May 2018; Revised 20 July 2018; Accepted 31 July 2018; Published 16 September 2018

Academic Editor: Guang Xu

Copyright (c) 2018 Yanhai Zhao et al. This is an open access article distributed under the Creative Commons Attribution License, which permits unrestricted use, distribution, and reproduction in any medium, provided the original work is properly cited.

To reveal the performance of the stepped subsidence and the strong roof weighting during shallow coal mining, taking the fully mechanized mining face with large mining height in the Shendong mining area in China as the engineering background, theoretical analysis and numerical simulation were used to analyze the pressure-arching effect of the hanging roof blocks. Three typical pressure-arch models of the roof structure were proposed, such as the symmetrical pressure-arch of two key blocks, the step pressure-arch of multiple key blocks, and the rotative pressure-arch of multiple key blocks. Results indicate that the horizontal stress displays a nonlinear distribution at the abutments of the symmetrical pressure-arch, and there is a linear distribution of horizontal stress with a higher peak value at the midspan of the pressure-arch. The high horizontal stress at the arch abutment is necessary to form the rotative pressure-arch of multiple key blocks. The horizontal stress is relatively less at the arch abutment of the step pressure-arch structure. The main key block is easier to slide in this structure as the boundary horizontal stresses display the nonlinear distribution. The results are of instructive significance for roof weighting forecast and strata control during shallow horizontal mining for a thick coal seam.

\section{Introduction}

The shallow coal resource is huge in western China, but the fragile ecological environment and mining-induced disaster also restricted the development of the mining area seriously. The Shendong mining area in western China was characterized by large thickness, shallow buried, and flat dipping coal seams, which was a typical high efficiency mining district of shallow thick coal mining and the largest underground coal mining area in the world. The fully mechanized longwall mining with large mining height was widely used in this district, and the width of the panel can be reached at $450 \mathrm{~m}$.

The roof weighting and ground subsidence induced by shallow coal mining also affected the development of similar mining engineering in the world [1-3]. So it is an important problem to reveal the performance of the stepped subsidence and the strong roof weighting during shallow coal mining. The large-scale shallow mining for full thickness of coal increased the failure range of the thin bedrock roof, and the load of fractured strata was not carried effectively by the roof block structure, resulting in strong mine pressure. So the mechanical model was widely used in analyzing the roof structure and weighting forecast, and the application of the voussoir beam model, cantilever beam model, Euler beam model, and hinged arch bar model also proved its practicality in many engineering cases [4]. The fully mechanized mining for thick coal with large mining height would aggravate the shallow strata movement, the moving law and structure types of the roof blocks were special in these cases, and the weighting step and load intensity were characterized by alternating with long and short periods. So the slip instability of the roof blocks would cause the movable column being retracted sharply, and then the supports were being crushed.

Aiming at these problems, a great deal of research has been conducted. For examples, Ju and Xu used the cantilever and voussoir beam structural models to reveal the periodic 
alternating law of the weighting step and strata behavior through field observation on the longwall face with $7.0 \mathrm{~m}$ mining height and pointed out that the key strata broken in advance and step subsidence would lead to the periodical changes in gentle and strong roof weighting [5]. Liu et al. carried out the simulation experiment on large height mining of the thick coal in a mine by using FLAC $^{3 \mathrm{D}}$, and the results showed that the height of the fractured zones increased with the mining thickness of the shallow coal seam [6]. Through physical similarity tests, Ren et al. pointed out that the bedrock fissure zone conducting surface was the main cause of the long and short periodical roof weighting during the shallow mining [7]. Zhang et al. conducted the numerical simulation on a working face in the Shendong mining area by using UDEC and proposed that if the basic roof could form a stable bearing structure, the overlying strata would present a continuous bending down without slip instability and whole step subsidence [8]. Huang et al. found that the inclined step rock beam of the key strata was a common structure type in the mining field with superlarge mining height in the Shendong mining area [9].

The cantilever beam [4, 10] and voussoir beam [11-13] models were widely applied in analyzing the roof weighting, but these models in previous studies mostly were to estimate the horizontal thrust between roof blocks and the action position by empirical formulas, not taking into account the effects of the stress distribution on the structure stability. However, the slip instability and rotational deformation were usually all affected by the horizontal stress [14]. BakunMazor et al. indicated that the horizontal stress distribution along the boundary of the key roof blocks was not necessarily linear and the exact geometry distribution of that stress must be determined by the experimental studies [15]. Tsesarsky studied the arching law of the compressive stress within the layered sedimentary rocks in shallow mining by using FLAC and analyzed the effects of block size and joint space on the horizontal stress distribution [16]. Shabanimashcool et al. [17] and Helm et al. [18] found that the maximum span of the voussoir roof beam prior to the first roof caving depended upon the initial horizontal stress and the roof beams formed a large stable span when they were subjected to the high horizontal stress.

Due to the current models of the roof structures being paid more concerns on the gravity effect on the stability of the roof blocks, the arching law of the principle stress and boundary horizontal stress distribution were not well recognized; ignoring the influence of the pressure-arch structure on the roof movement behavior, the fractured roof of the large height working face under shallow mining for thick coal displayed obvious step subsidence, frequently support crushing accident, and commonly ground cracks $[1,9]$, and these abnormal performances induced by shallow mining were still not being explained reasonably. In this paper, the fully mechanized mining face with large mining height in the Shendong mining area in China was taken as the engineering background, and theoretical analysis and numerical simulation were used to analyze the pressure-arching effect and the distribution of the horizontal stress in the roof block structure. It was of guiding significance for obtaining the instability and roof weighting characteristics of the pressurearch structure in the key roof blocks to ensure shallow mining safety.

Since there are still many problems needed to be solved in the shallow coal mining, this paper would conduct further study on the roof weighting of a typical shallow coal mining. Taking the fully mechanized mining face with large mining height in the Shendong mining area as the engineering background, theoretical analysis and numerical simulation were used to analyze the arching law of the principle stress and the distribution of the horizontal stress in the roof block structure. Considering that the pressure-arch effect in the roof blocks can improve the rationality of the mechanical model, three typical pressure-arch models of the roof structure were proposed and the related instability criteria were derived. The results are of important meaning for safety mining in the similar engineering.

The remainder of this study was organized as follows. In Section 2, structural characteristics of key blocks and their verification analysis of the typical engineering under shallow coal mining are conducted. In Section 3, the evolution process of the pressure-arch in the key blocks during coal mining is analyzed. In Section 4, the discussion of the results is provided. Section 5 summarizes the conclusions.

\section{Pressure-Arching Characteristics}

2.1. Symmetric Pressure-Arch of Two Key Blocks of Initial Fractured Roof. As shown in Figure 1, with the mining face advancing from the open-off cut, the cracks were generated at both ends and the midspan of the basic roof when reaching its limit span, forming trapezoid and arc blocks. The basic roof was periodically broken into multiple removable trapezoid blocks in the middle of the working face. The movements of these arc blocks at both sides were controlled by the trapezoid blocks.

The original fractured blocks $F_{\mathrm{a}}, F_{\mathrm{b}}$ and periodic fractured blocks $P_{\mathrm{a}}, P_{\mathrm{b}}$ continuously sank and contacted the waste rocks, and the hanging blocks were squeezed with the rear blocks to form the fractured structure. The stability of the fractured roof structure depended on the movement of the key blocks, while the slip instability of the main block over the support was a direct factor to induce roof cutting and strong strata behavior.

After the full thickness of the coal seam being mined, the caving immediate roof was not enough to fill the goaf, so the large mining height technology provided a movable space for the roof blocks. The hanging blocks showed the step structures after separating from the upper strata. The roof weighting for sliding blocks was stronger than the normal height mining [9]. The middle of the mining face was the critical control area as roof weighting, so it was feasible to analyze the movement of key roof blocks by using the plane model.

The symmetrical pressure-arch model of two key blocks was established, as shown in Figure 2. After the basic roof original breaking, the separated roof blocks rotated under their weights and were compressed reciprocally at the abutments in the surface contact state. The friction and 


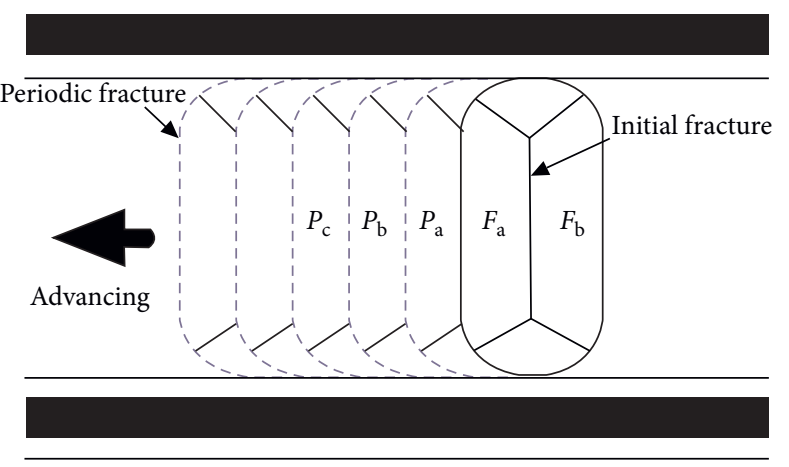

FIGURE 1: Typical geometry structure of the fractured roof blocks.

horizontal thrust at the abutments directly affected the instability types of the roof blocks, and the internal and boundary stress distribution of the blocks was essential to the stability analysis of the roof structures.

The horizontal stress $\sigma_{x x}$ at the left abutment of the block (Figure 2(c)) was distributed [15]:

$$
\sigma_{x x}=f(x)=a(x-h)^{b},
$$

where $h$ is the distributed height of the horizontal stress at the left abutment, $f(x)$ is the distribution function of the horizontal stress, and $x$ is the coordinate position.

The horizontal stress $\sigma_{x x}$ at the coordinate origin point $\mathrm{O}$ was the largest value at $x=0$; the maximum value of the stress $\sigma_{\mathrm{m}}=f(0)=a(-h)^{b}$ according to the stress distribution law in Equation (1); the horizontal thrust $T$ and its position $X_{T}$ were, respectively, given by

$$
\begin{aligned}
T & =\int_{0}^{h} a(x-h)^{b} d x=\frac{a h(-h)^{b}}{b+1}=\frac{\sigma_{\mathrm{m}} h}{b+1}, \\
X_{T} & =\frac{1}{T} \int_{0}^{h} f(x) x d x=\frac{h}{b+2} .
\end{aligned}
$$

Assuming that the boundary stress distribution of the contact surface was the same, the horizontal thrust $T$ was equal. If the pressure-arch structure of key blocks was in the equilibrium state, taking the moment at the left point $\mathrm{O}$, then $\sum M_{O}=M_{Q_{N}}-M_{w}=0, \sum Y=2 W-Q_{O}-Q_{N}=0$.

So the equilibrium equation was given by

$$
\begin{gathered}
Q_{N}(2 L \cos \alpha+2 H \sin \alpha)-W(0.5 L \cos \alpha+H \sin \alpha) \\
-W(1.5 L \cos \alpha+H \sin \alpha)=0 \\
Q_{O}+Q_{N}=2 W
\end{gathered}
$$

where $Q_{O}, Q_{N}$ are the shear force, $H$ is the block height, $\alpha$ is the rotating angle, $W$ is the bearing load of the roof block, namely, $\gamma L\left(H+H_{1}\right), \gamma$ is the unit weight of the roof rock, and $H_{1}$ is the thickness of the upper loading layer.

Arranging Equations (4) and (5), then

$$
Q_{O}=Q_{N}=\gamma L\left(H+H_{1}\right) \text {. }
$$

The roof block $F_{\mathrm{a}}$ was the main key block over the mining working face. The slip instability of the block $F_{\mathrm{a}}$ would lead to the roof step subsidence and strong pressure on the support. However, the instability could be avoided when the contact friction, $T \tan \varphi$, was larger than the shear force $Q_{O}$, namely, $T \tan \varphi>Q_{O}$.

Substituting Equations (2) and (6) into the abovementioned inequality, then

$$
\sigma_{\mathrm{m}}>\frac{\gamma L(b+1)\left(H+H_{1}\right)}{h \tan \varphi} .
$$

\subsection{Step Pressure-Arch Structure of Key Blocks of the Periodic} Fractured Roof. As shown in Figure 3, with the mining face advancing, the basic roof was fractured periodically. Field observation and simulation experiment showed that the quantity of removable blocks that affected the stability of the mining face was limited, so only the migration of key blocks hanging above the support space was worth considering.

The typical step pressure-arch structure of multiple key blocks is shown in Figure 3(a). The rotating angle $\alpha_{1}$ of the main block $P_{\mathrm{a}}$ was larger than the angle $\alpha_{2}$ of the rear block, and the block $P_{\mathrm{a}}$ contacted with adjacent blocks at the hinged ends, and then a semiarch of stress formed in the main block. The rear blocks $P_{\mathrm{b}}$ and $P_{\mathrm{c}}$ with little rotating angle compressed mutually and slid to form a step structure under the action of the horizontal thrust and shear force.

To analyze the mechanics of the key blocks $P_{\mathrm{a}}$ and $P_{\mathrm{b}}$, taking the moment at the left hinged point $A, \sum M_{A}=0$, since the vertical resultant force was zero, let, $\sin \alpha_{1}+\sin \alpha_{2}=A_{1}$, $\cos \alpha_{1}+\cos \alpha_{2}=A_{2}$, and then the following equilibrium was given:

$$
\begin{aligned}
& T\left(H-L A_{1}-2 X_{T}\right)-W\left(1.5 L \cos \alpha_{1}+0.5 L \cos \alpha_{2}+2 H \sin \alpha_{1}\right) \\
& \quad+Q_{B}\left(L A_{2}+H \sin \alpha_{1}\right)=0
\end{aligned}
$$

$$
Q_{A}+Q_{B}=2 W
$$

Combining Equations (8) and (9), then

$$
\begin{aligned}
Q_{B}= & \frac{W\left[0.5 L\left(2 \cos \alpha_{1}+A_{2}\right)+2 H \sin \alpha_{1}\right]}{L A_{2}+H \sin \alpha_{1}} \\
& -\frac{T\left[H-L A_{1}-2 X_{T}\right]}{L A_{2}+H \sin \alpha_{1}}, \\
Q_{A}= & \frac{0.5 W L\left(A_{2}+2 \cos \alpha_{2}\right)+T\left[H-L A_{1}-2 X_{T}\right]}{L A_{2}+H \sin \alpha_{1}} .
\end{aligned}
$$

For the main block $P_{\mathrm{a}}, \tan \varphi$ was the friction coefficient of the contacted surface; if $T \tan \varphi<Q_{A}$, the block would slide along the working face. According to Equations (2), (3), and (11), let $\sin \alpha_{1} \tan \varphi=A_{3},(2 h /(b+2))=A_{4}$, and then the following formula was obtained:

$$
\sigma_{\mathrm{m}}<\frac{0.5 \gamma L^{2}(b+1)\left(A_{2}+2 \cos \alpha_{2}\right)\left(H+H_{1}\right)}{h\left[L \tan \varphi A_{2}+H\left(A_{3}-1\right)+L A_{1}+A_{4}\right]}
$$

Equation (12) can be used as the slip instability criterion for the main block in this structure. 


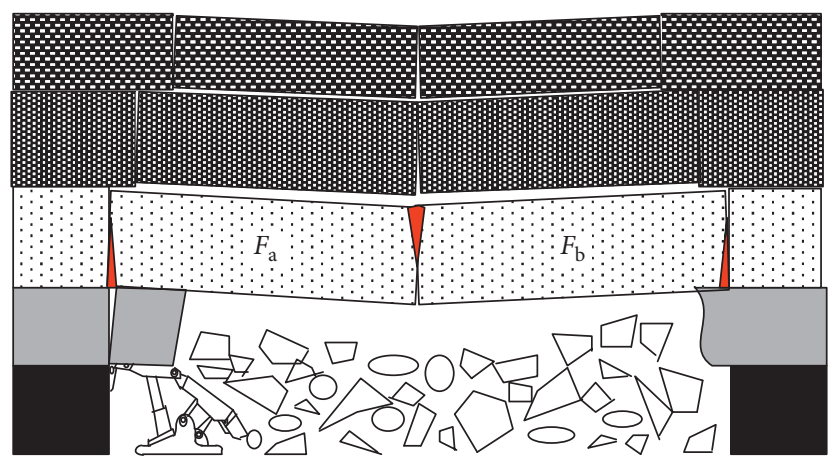

(a)

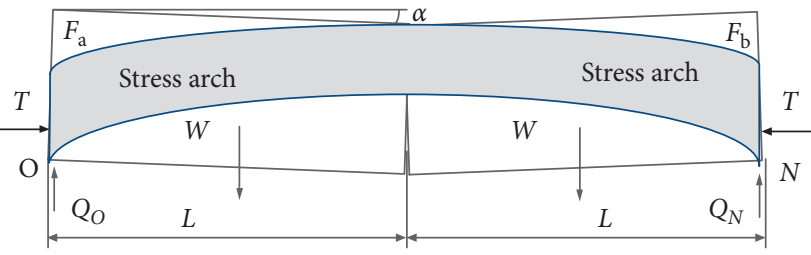

(b)

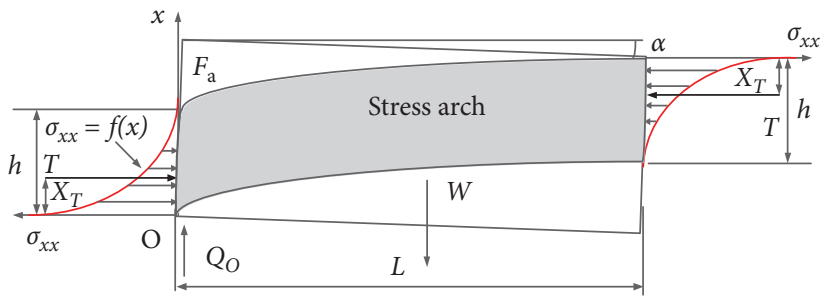

(c)

Figure 2: Pressure-arch structure of two key blocks of the initial fractured roof. (a) Sketch map of the structure of key blocks. (b) Mechanical model. (c) Boundary stress distribution at the abutment.

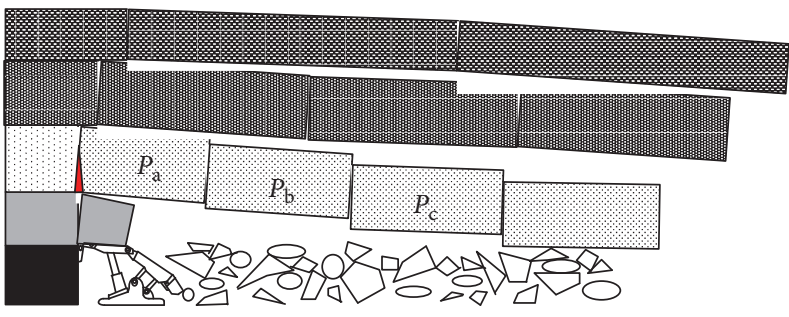

(a)

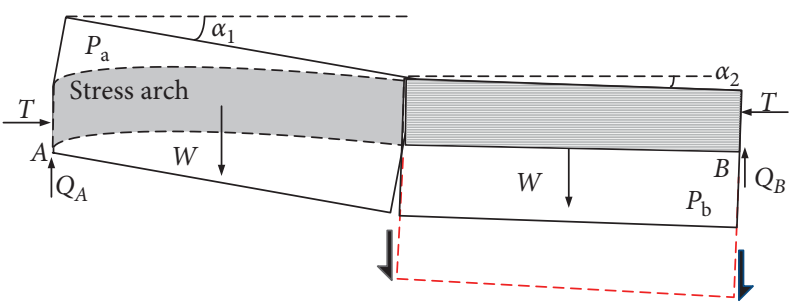

(b)

FIGURE 3: Step pressure-arch structure of key blocks of the periodic fractured roof. (a) Sketch map of the structure of key blocks. (b) Mechanical model.

2.3. Rotative Pressure-Arch Structure of Key Blocks of the Periodic Fractured Roof. The rotative pressure-arch structure of the multiple key blocks was shown in Figure 4(a). The rotating angle of each block was approximately equal, and the horizontal thrusts among these blocks were sufficient to mobilize a frictional resistance to balance the shear force. The roof blocks rotated gradually without slip instability, and the rotative pressure-arch with bearing capacity produced a protective effect on the mining space.

The moment at the left hinged point $A \sum M_{A}=0$, and the vertical resultant force was zero, and then the equations were given as follows:

$$
\begin{gathered}
T\left(H-3 L \sin \alpha-2 X_{T}\right)+Q_{B}(3 L \cos \alpha+H \sin \alpha) \\
-W(4.5 L \cos \alpha+3 H \sin \alpha)=0 \\
Q_{A}+Q_{B}=3 W .
\end{gathered}
$$

Combining Equations (13) and (14), then

$$
\begin{aligned}
Q_{B} & =\frac{W(4.5 L \cos \alpha+3 H \sin \alpha)}{3 L \cos \alpha+H \sin \alpha}-\frac{T\left(H-3 L \sin \alpha-2 X_{T}\right)}{3 L \cos \alpha+H \sin \alpha} \\
Q_{A} & =\frac{4.5 W L \cos \alpha+T\left(H-3 L \sin \alpha-2 X_{T}\right)}{3 L \cos \alpha+H \sin \alpha}
\end{aligned}
$$

The roof block sliding should be avoided to ensure the formation of the structure, namely, $T \tan \varphi>Q_{A}$.

Substituting Equations (2), (3), and (16) into this inequality, and letting $\sin \alpha_{1} \tan \varphi=A_{3}$ and $(2 h /(b+2))=A_{4}$, then

$$
\sigma_{\mathrm{m}}>\frac{4.5 \cos \alpha \gamma L^{2}(b+1)\left(H+H_{1}\right)}{h\left[3 L(\tan \varphi \cos \alpha+\sin \alpha)+H\left(A_{3}-1\right)+A_{4}\right]} .
$$

2.4. Stability Analysis of the Main Key Block of the Initial Fractured Roof. Taking No. $1^{-2}$ coal with $7.0 \mathrm{~m}$ mining height at the Shangwan mine in Shendong mining area as the 


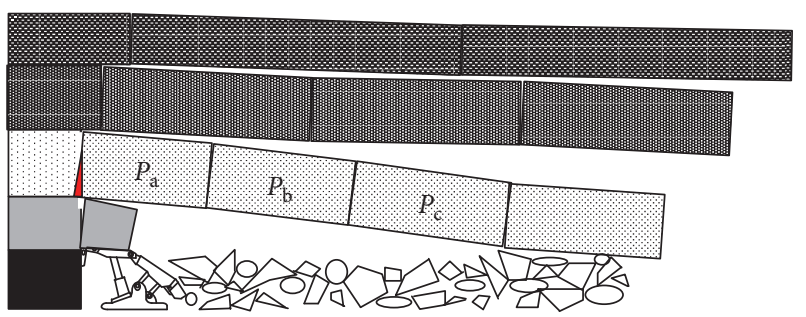

(a)

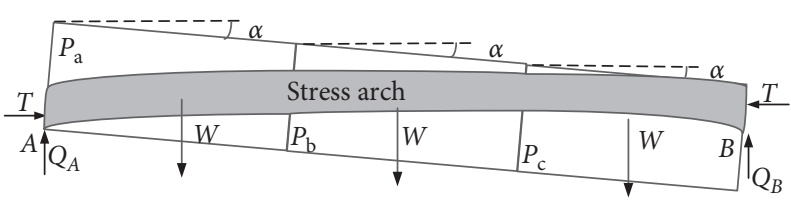

(b)

FIGURE 4: Rotative pressure-arch structure of key blocks of the periodic fractured roof. (a) Sketch map of the structure of key blocks. (b) Mechanical model.

engineering background, the panel was at an average depth of $115.4 \mathrm{~m}$, which dipped $0-3^{\circ}$. The thickness of coal was $3.8-9.2 \mathrm{~m}$ and $7.0 \mathrm{~m}$ thick in average. The average thickness of the ground overburden of alluvial sand was $13.7 \mathrm{~m}$, and the average thickness of the bedrock was $102.1 \mathrm{~m}$.

The length of the fully mechanized mining panel No. 51101 was $3654 \mathrm{~m}$, the width was $300 \mathrm{~m}$, and the designed mining height of the panel was $5.2-5.4 \mathrm{~m}$. The total caving method to manage roof was adopted, which matched the German Eickhoff SL-500 shearer, and double column shield hydraulic supports $2 \times 4319 \mathrm{kN}$.

The immediate roof of the mining field was mostly sandy mudstone or siltstone, whose thickness was $0.5-7.1 \mathrm{~m}, 3.0 \mathrm{~m}$ in average. The basic roof was sandstone, whose thickness was $6-15.1 \mathrm{~m}, 9 \mathrm{~m}$ in average, and the compressive strength of that was $16.6-33.8 \mathrm{MPa}, 25 \mathrm{MPa}$ in average. The span of the initial roof weighting step was $53.8 \mathrm{~m}$, and there was six times periodic roof weighting in all during the field observation. The span of the roof weighting in the middle of the mining face was $10.9-32.7 \mathrm{~m}, 20.39 \mathrm{~m}$ in average.

Based on the technical parameters of panel No. 51101, the thickness $H$ of the basic roof was $9 \mathrm{~m}$, and the block length $L$ was $26.9 \mathrm{~m}$ according to the initial roof weighting step. The rotating angle $\alpha$ was taken as $4^{\circ}$, the friction coefficient $\tan \phi$ was 0.5 , the bulk density of the roof was $25 \mathrm{kN} / \mathrm{m}^{3}$, and the compressive strength $\sigma_{\mathrm{c}}$ was $25 \mathrm{MPa}$. As shown in Figure 5, the curves were calculated from Equation (7), which was used to judge the stability of the main block in the symmetrical stress arch structure. The slip instability was avoided when the maximum horizontal stress reached the curve value $\sigma_{\mathrm{m}}$. The variable $h$ in Figure 5 was the abutment thickness of the stress arch.

The following results were found: (1) When the boundary horizontal stress displayed the nonlinear distribution, the stable stress $\sigma_{\mathrm{m}}$ of the block was higher, so the block with nonlinear boundary stress was easier to slide under the same crustal stress condition. (2) When the abutment thickness $h$ of the pressure-arch was $0.1 H$ for the nonlinear boundary stress, the maximum horizontal stress needed to reach $40 \mathrm{MPa}$ to ensure the blocks without sliding, while the stress $\sigma_{\mathrm{m}}$ had exceeded the compressive strength of the blocks under this condition, so the plastic failure at the hinged end of the blocks occurred, which led to further rotation of the roof blocks. (3) The critical stress $\sigma_{\mathrm{m}}$ decreased with the thickness $h$ increasing, the decreasing trend was most obvious in the range of $0.1-0.3 \mathrm{H}$, and this trend

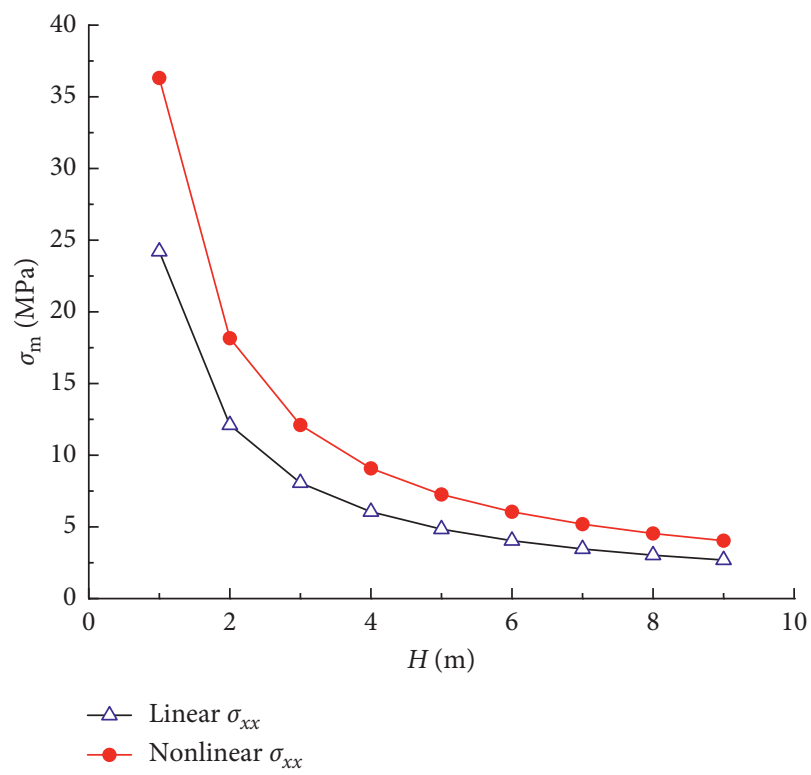

FIGURE 5: Stability curve of the symmetric pressure-arch structure of two key blocks.

indicated that it no longer required a high level of stress to avoid the slip instability when the pressure-arch abutment reached a certain thickness.

Therefore, the decreasing stress reduced the plastic failure of the block ends and prevented further rotation to increase roof weighting. So the increasing abutment thickness of the pressure-arch could improve the stability of the key blocks.

2.5. Stability Analysis of the Main Key Block of the Periodic Fractured Roof. According to Equations (12) and (17), the rotating angle $\alpha_{1}$ and $\alpha_{2}$ of the key blocks in the step pressure-arch structure was adopted, respectively, as $4^{\circ}$ and $1^{\circ}$, and the rotating angle $\alpha$ of the key blocks in the rotative pressure-arch structure was adopted as $4^{\circ}$. The length $\mathrm{L}$ of the block was $20 \mathrm{~m}$ according to the periodic weighting step, and the other parameters remain unchanged. The stability judging curves of the step pressure-arch and the rotative pressure-arch structure were obtained, as shown in Figure 6.

The following results were found: (1) The horizontal stress needed to maintain the stability of the multiple key blocks' structure which was higher than that of the symmetrical pressure-arch structure of two key blocks. With the 


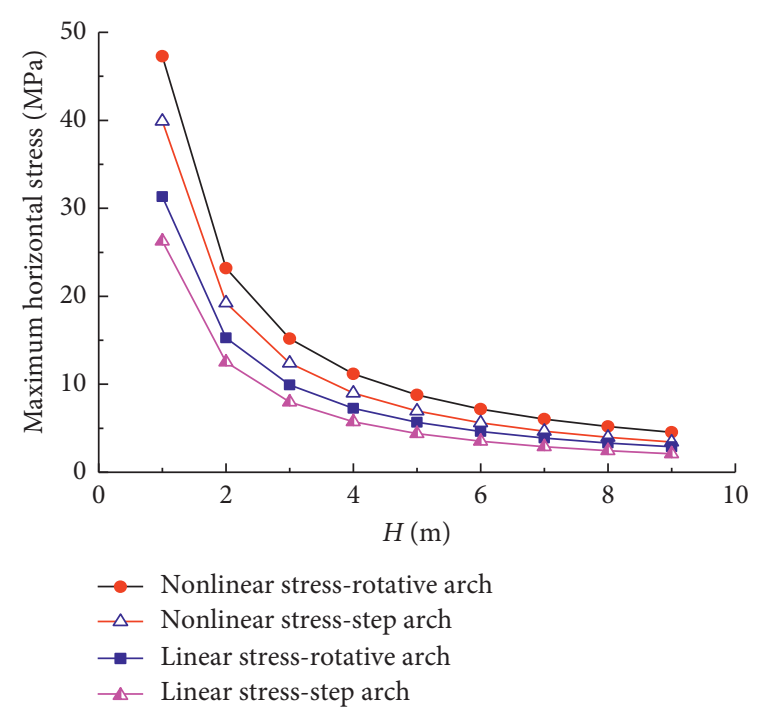

FIgURE 6: Stability curves of the pressure-arch structure of multiple key blocks.

abutment thickness of the pressure-arch being less than $0.2 \mathrm{H}$, the maximum horizontal stress $\sigma_{\mathrm{m}}$ would exceed the compressive strength $\sigma_{c}$ of the blocks, and the plastic failure occurred at the hinged end of the block. (2) The stable horizontal stress of the rotative pressure-arch was the largest under the same ground stress condition, and the rotative pressure-arch was more difficult to form. (3) The pressurearch with smaller abutment thickness required higher stress to maintain the stability of the key blocks, and the greater plastic failure would occur at the block ends.

\section{Evolution Characteristics of Pressure-Arch}

3.1. Building Computational Model. Based on the geological condition and the mining field in the Shanwan mine, the discrete element software UDEC was used to analyze the instability characteristics of the pressure-arch of key blocks under the shallow coal mining condition. The numerical test was to simulate the mechanical behavior of the fractured strata blocks, considering the vertical and horizontal virtual joints' condition, the normal stiffness and tangential stiffness of each joint can be approximately calculated through the joint structure and the deformation of intact rock mass, so the normal stiffness and tangential stiffness were set as 4.0 $\mathrm{GPa} / \mathrm{m}$.

As shown in Figure 7, the full mining thickness of the coal seam was $7 \mathrm{~m}$, and the thickness of the immediate roof was $3 \mathrm{~m}$. Considering the falling size of the immediate roof, the virtual joint space was set as $3 \mathrm{~m}$. The thickness of the basic roof was $9 \mathrm{~m}$. Since the periodic weighting length was $10.9-32.7 \mathrm{~m}$ in the practical engineering, this numerical test was focused on the stress distribution in the strata blocks during shallow coal mining, so the virtual block size was set as $15 \mathrm{~m}$ in the basic roof according to the weighting length.

The thickness of the strata over the basic roof was set as $30 \mathrm{~m}$ to focus on the movement law of the roof strata. According to the field observation and similar material experiment results, the thickness/span ratio of the broken strata decreased with the layer position rising, the fractured strata block in high position was longer the basic roof block $[4,10]$, so the length of a single virtual block was set as $30 \mathrm{~m}$, $25 \mathrm{~m}$, and $20 \mathrm{~m}$ in strata (1)-(3) in Figure 7, respectively.

The model size was $450 \mathrm{~m}$ long and $54 \mathrm{~m}$ high, and the upper boundary loading was calculated as the bedrock strata of $70 \mathrm{~m}$ thickness. The bottom boundary of the model was fixed, and the lateral boundaries of the model were fixed in the horizontal direction.

The position of start mining was $50 \mathrm{~m}$ away from the left boundary, and the advancing distance was $350 \mathrm{~m}$. The monitoring line was arranged along the $Y$ direction at the interval of $1 \mathrm{~m}$ in the range of $15-24 \mathrm{~m}$ to obtain the evolution law of the stress field and displacement field in the roof structure during mining. The physical and mechanical parameters of the model were listed in Table 1, and MohrCoulomb criteria were used in the numerical calculation.

3.2. Evolution Process of the Pressure-Arch of Key Blocks during Coal Mining. For mining face No. 51101, advancing $10 \mathrm{~m}$ each time was adopted in the simulation. As shown in Figure 8(a), the compressive stress was positive, while the tensile stress was negative, and the principle stress showed an obvious arching effect in the initial stage of coal mining. As the advancing distance was $30 \mathrm{~m}$, the immediate roof displayed the initial caving, the symmetrical pressure-arch formed in the basic roof, and the global pressure-arch formed in the overlying strata. Overall, the roof kept stable. The monitoring data showed that the peak value of the major principle stress occurred at the abutment of the pressure-arch and the maximum horizontal stress at both abutments was $1.72 \mathrm{MPa}$ and $1.81 \mathrm{MPa}$, respectively.

As shown in Figure 8(b), the initial caving of the basic roof occurred when the advancing distance was $50 \mathrm{~m}$, and the load of the fallen roof blocks was transferred to the surrounding rock by the squeezing and clamping between the blocks. The principle stress was redistributed and delivered through the contacting face. The step pressure-arch structure formed in the main key blocks and the fallen roof blocks moved along the stress transferring trace. The peak value of major principle stress occurred at the surrounding rock of mined-out area, and the maximum horizontal stress at the right arch abutment was $2.41 \mathrm{MPa}$, but the maximum horizontal stress on the surface of the sliding block was only $0.41 \mathrm{MPa}$.

As shown in Figure 9(a), the overlying bedrock strata were moved totally with the mining face advancing $210 \mathrm{~m}$, the coal mining reached the complete mining stage, and the global pressure-arch structure of the bedrock strata was transformed into the single pressure-arch structure in each layer. The rotating angle of the basic roof block increased significantly compared with the previous state, the front half pressure-arch formed in the hanging basic roof at the mining face side, and the pressure-arch top was located in the step sliding basic roof block at the midspan of the mined-out area. The hanging basic roof carried the upper strata load and was kept stable by the structure effect of the pressurearch, and the roof weight was relatively weak in this period. 


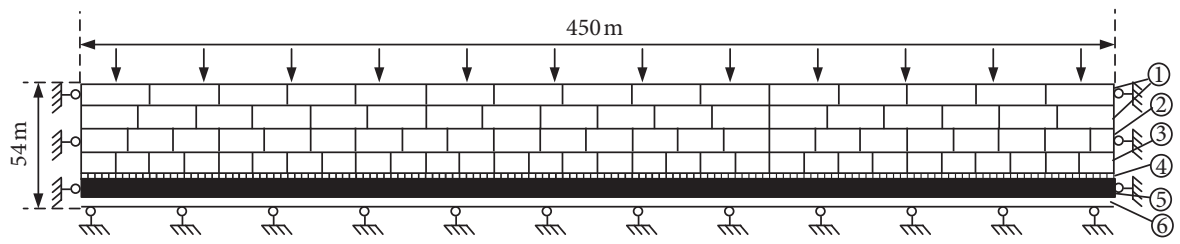

Figure 7: The computational model: (1) sandstone; (2) coarse sandstone; (3) sandstone; (4) mudstone; (5) coal; (6) siltstone.

TABle 1: Physical and mechanical parameters of the materials.

\begin{tabular}{|c|c|c|c|c|c|c|}
\hline Name & $\begin{array}{l}\text { Unit weight } \\
\left(\mathrm{kN} / \mathrm{m}^{3}\right)\end{array}$ & $\begin{array}{c}\text { Elastic modulus } \\
(\mathrm{GPa})\end{array}$ & $\begin{array}{l}\text { Poisson's } \\
\text { ratio }\end{array}$ & $\begin{array}{c}\text { Cohesive strength } \\
(\mathrm{MPa})\end{array}$ & $\begin{array}{c}\text { Tensile strength } \\
(\mathrm{MPa})\end{array}$ & $\begin{array}{l}\text { Friction } \\
\text { angle }\left({ }^{\circ}\right)\end{array}$ \\
\hline Coarse sand-stone & 24.3 & 35 & 0.23 & 5.5 & 4 & 33 \\
\hline Sand-stone & 25.0 & 32 & 0.24 & 7.3 & 4.9 & 35 \\
\hline Mud-stone & 22.4 & 23 & 0.15 & 2.5 & 1.7 & 30 \\
\hline Coal & 13.1 & 15 & 0.29 & 0.79 & 0.57 & 27 \\
\hline Silt-stone & 24.6 & 26 & 0.22 & 3.9 & 2.5 & 38 \\
\hline
\end{tabular}

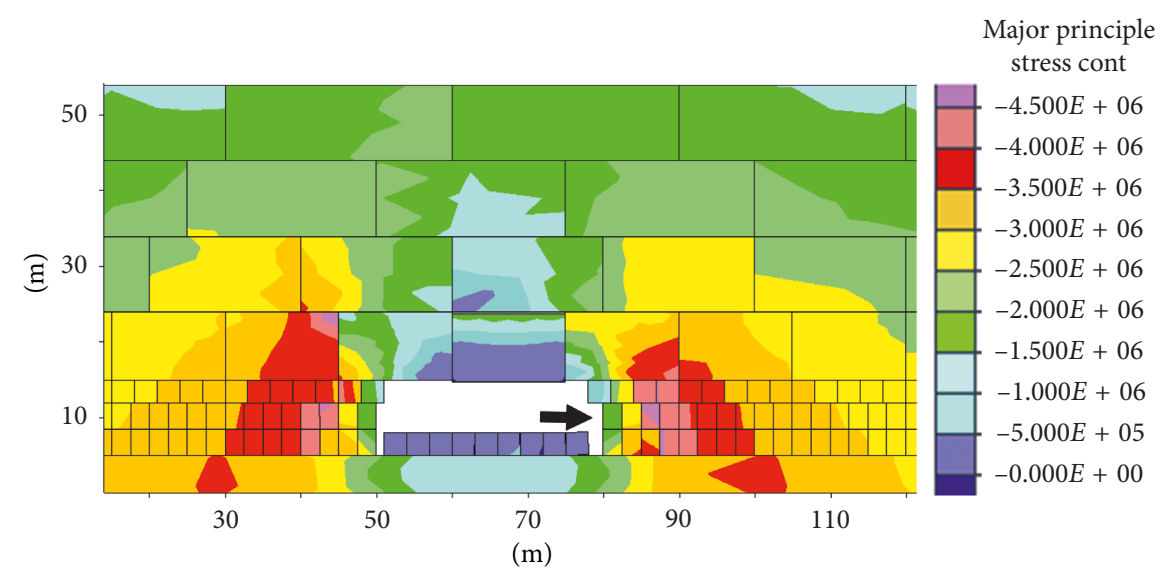

(a)

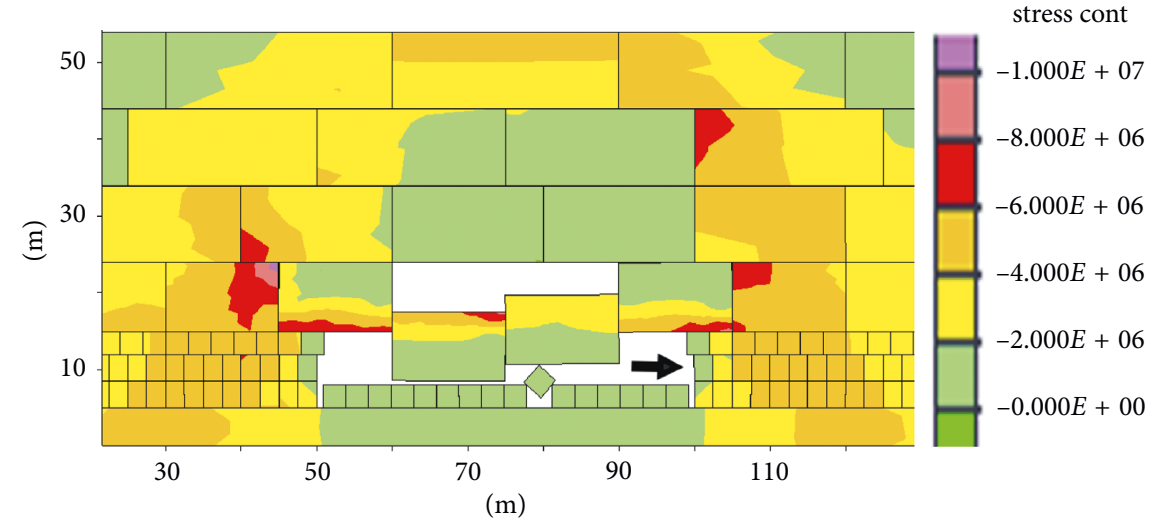

(b)

FIGURE 8: Evolution process of the pressure-arch in the initial mining stage. (a) Initial caving of the immediate roof. (b) Initial caving of the basic roof.

It can be seen from Figure 9(b) that, with the mining face advancing $230 \mathrm{~m}$, multiple layers of the bedrock strata rotated and sank toward the mined-out area, and the sank roof strata were compacted in the range of abscissa of 190-220 m. The pressure-arch structure of basic roof produced instability under the dynamic load of the upper strata during this structure rotation process, the step sliding basic roof blocks in the pressure-arch top reached maximum subsidence, and the rotated instability of basic roof in the front pressure-arch would increase the resistance of the support at the working face side. 


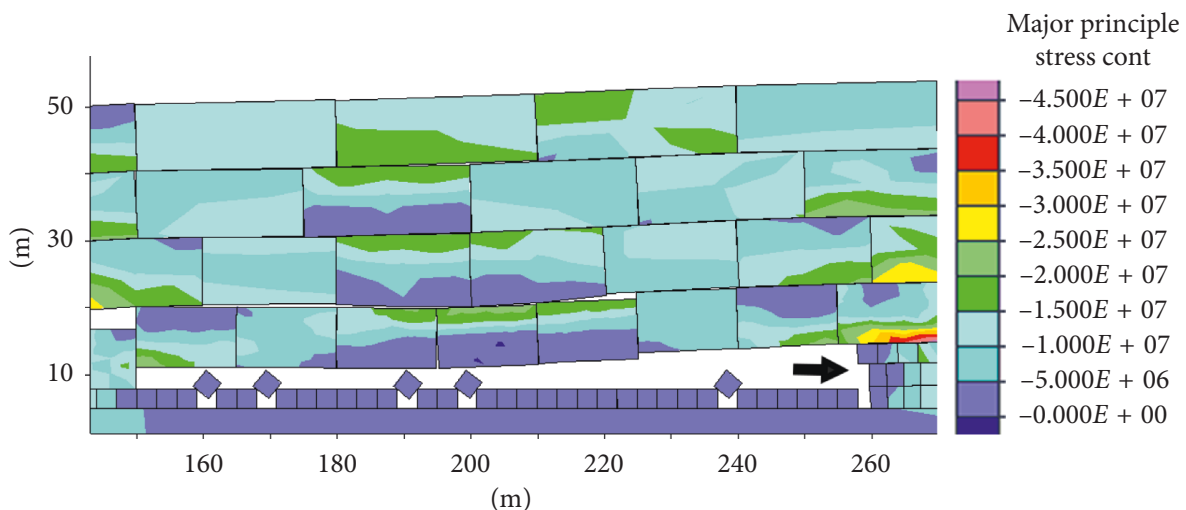

(a)

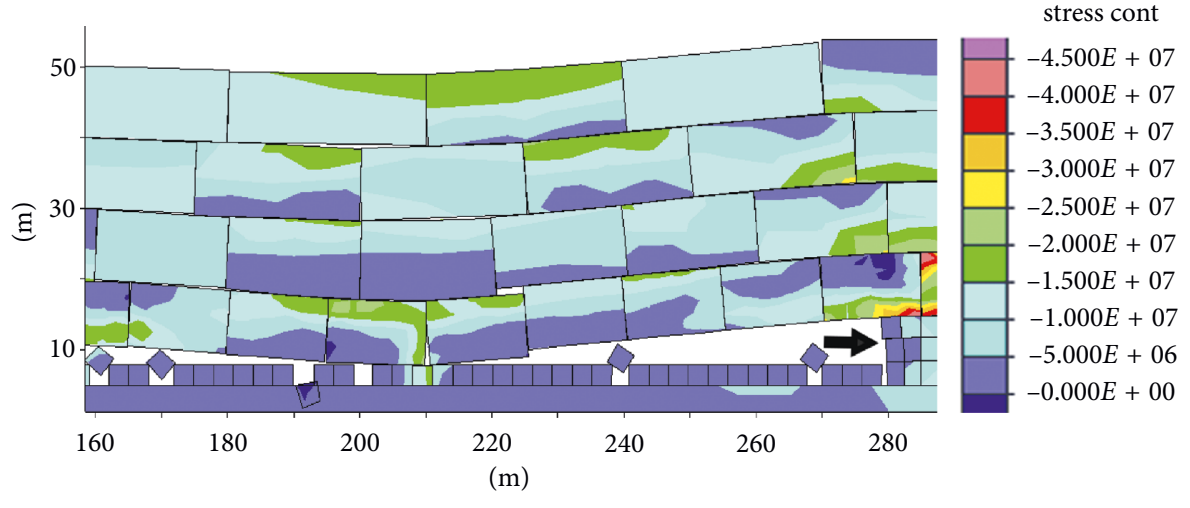

(b)

FIGURE 9: Evolution process of the step pressure-arch structure of the basic roof. (a) Step pressure-arch. (b) Instability of the pressure-arch of the basic roof.

Compared with the stable state of the pressure-arch in the basic roof, the instability of the pressure-arch in the hanging basic roof led to the load of the upper bedrock strata losing carrier; the additional load acting on the roof support caused the strong periodic roof weighting.

As shown in Figure 10(a), with the mining face advancing $250 \mathrm{~m}$, the rotative pressure-arch structure was rebuilt in the basic roof, and the peak value of major principle stress at the left arch abutment was $50.23 \mathrm{MPa}$. As shown in Figure 10 (b), with advancing $280 \mathrm{~m}$, the basic roof sank toward the mined-out area and compacted at the midspan of the pressure-arch, and the peak value of major principle stress was $65.40 \mathrm{Mpa}$, the bearing load of the pressure-arch structure of the basic roof was transferred to the caved zone behind the mined-out area of the mining face side.

\subsection{Structural Characteristic Analysis of the Symmetrical} Pressure-Arch of Key Blocks. To explore the distribution characteristics of the symmetrical pressure-arch and the block size effect, different models were built considering the block length ranging from $10 \mathrm{~m}$ to $20 \mathrm{~m}$, and the length $L$ of the single block was increased $1 \mathrm{~m}$ for each time. As shown in Figure 11, the major principle stress distributed as the obvious symmetrical pressure-arch in the basic roof when the roof span reached $2 L$ gradually.
As shown in Figure 12, it was found that the horizontal stress at the pressure-arch abutments in the basic roof displayed the nonlinear distribution characteristics with quadratic function law. The stress $\sigma_{x x}$ decreased from the bottom to the top along the direction of the distributed height $h_{x}$, and the maximum horizontal stress was located at the lowest position of the arch abutments at $h_{x}=0$.

The horizontal stress at the midspan of the pressure-arch increased linearly from the bottom to the top along the direction of the height $h_{x}$, and the maximum horizontal stress $\sigma_{\mathrm{m}}$ at the midspan was greater than that at the abutments. The horizontal compressive stress was distributed in the range of $h_{x}=4-8 \mathrm{~m}$, and the midspan thickness of the arch was less than that of the abutments.

The peak value of the boundary horizontal stress increased with the block length increasing, and the maximum horizontal stress was $1.12 \mathrm{MPa}, 1.81 \mathrm{MPa}$, and $2.38 \mathrm{MPa}$ when the block length was $10 \mathrm{~m}, 14 \mathrm{~m}$, and $20 \mathrm{~m}$, respectively, while the abutment thickness of the pressure-arch reduced gradually with increasing span.

\section{Discussion of the Results}

The shallow coal mining with a large height would induce roof collapse, support crushing, and ground subsidence. The structure instability of the basic roof and overlying bedrock 


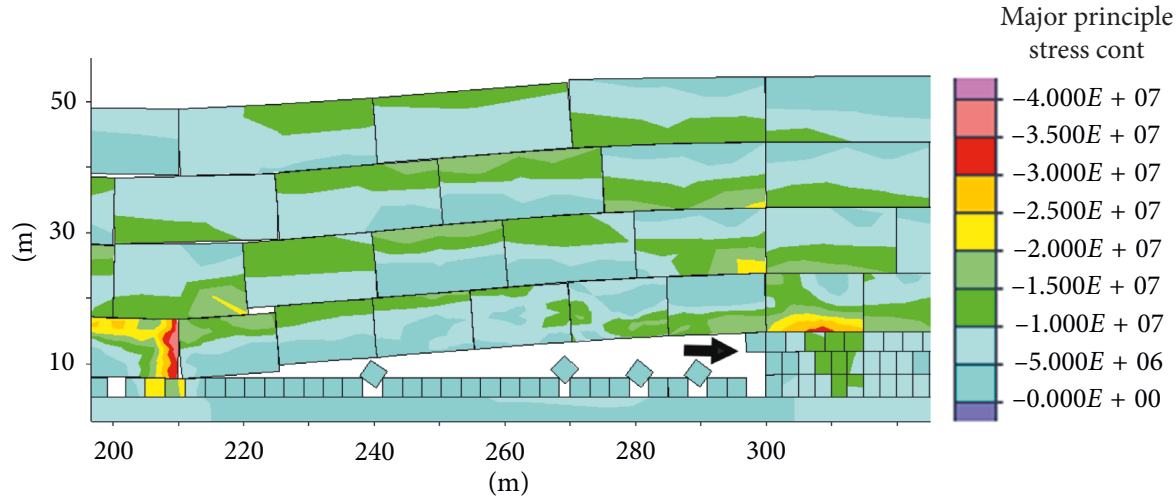

(a)

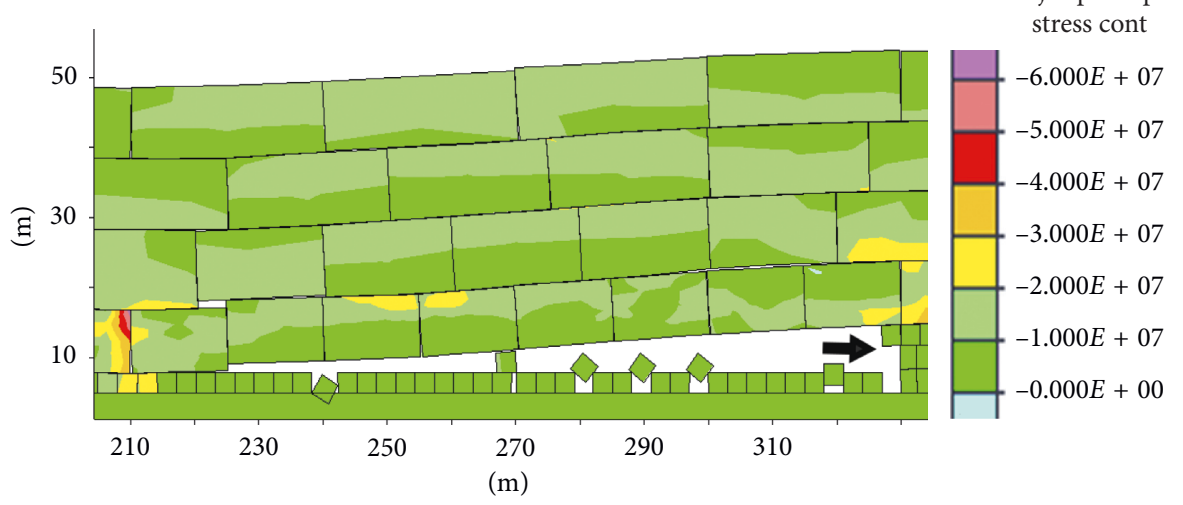

(b)

FIGURE 10: Evolution process of the rotative pressure-arch structure of multiple key blocks. (a) Rotative pressure-arch structure. (b) Sinking of the pressure-arch of the basic roof.

strata were the main cause of these mining damage, so it was very important to reveal the structure instability characteristics of the hanging roof blocks. Before the roof caving, the arching law of the principle stress made the roof block structure to have the capacity of bearing loading. The instability of the arch structure induced by mining often leads to the roof weighting. The load bearing structure of the roof blocks could be formed after the fully mechanized mining with large mining height, and the structural characteristic of the hanging blocks were more remarkable and the roof weighting would be unusually strong in the large mining space.

The symmetrical pressure-arch structure of the basic roof formed after the initial mining, and the horizontal stress at both sides of the arch displayed the nonlinear distribution, which was consistent with the findings of the literature [15]. But the horizontal stress was linearly distributed at the midspan of the arch, and the peak value of the horizontal stress was greater than that at both abutments, while the midspan thickness of the arch decreased.

Different views on the thickness of the arch were proposed [16]: (1) When the ratio of the arch thickness $h$ to the roof height $H$ was 0.75 , the arch structure was at equilibrium, and the ratio $h / H=0.3-0.4$, which was near failure. (2) When the ratio $h / H=0.3$, the arch structure was in the equilibrium state, while the ratio $h / H=0.1$, which was near failure. The results indicated that as the pressure-arch reached a certain thickness at the abutments, the required horizontal stress avoiding slip instability obviously reduced, and the increasing thickness of the pressure-arch could improve the stability of the key blocks. In addition, the distribution of the principle stress in blocks showed the size effect. With the block length increasing, the abutment thickness of the pressure-arch decreased and the midspan thickness kept unchanged; however, the peak value of the horizontal stress increased in all.

During the periodic fracture phrase of the roof, the pressure-arch structure still existed in the key blocks of the large height mining face, mainly behaving as the step pressure-arch structure of multiple key blocks and the rotative pressure-arch structure of multiple key blocks. Through mechanical analysis and numerical simulation, it was found that the sufficient horizontal stress was necessary to form the rotative pressure-arch structure, and the high horizontal thrust at the arch abutments made the load transfer along the arch trace in the blocks. This structure would not be maintained without strong horizontal constraint, and the horizontal stress on the surface decreased dramatically after the structure instability.

The horizontal stress was relatively lower at the arch abutment of the main key block in the step pressure-arch structure, the main key block was easier to slide under the nonlinear distributed boundary stress, and a step structure 


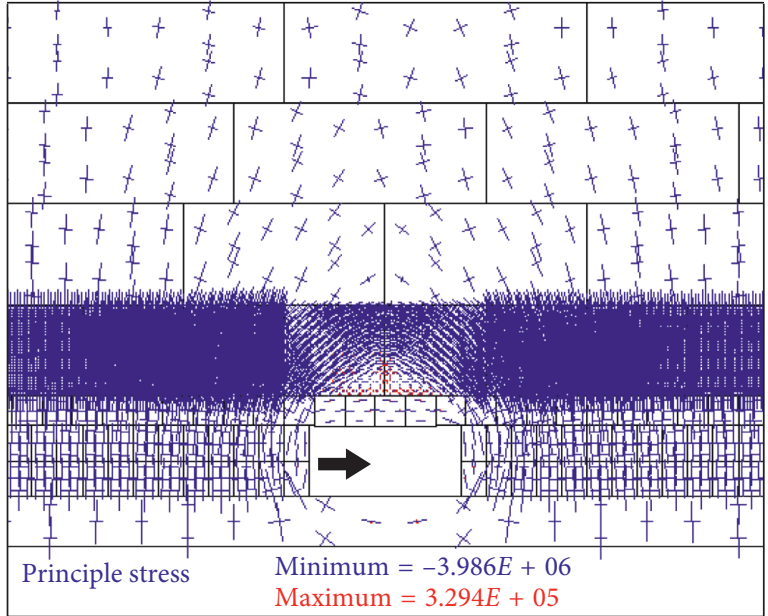

(a)

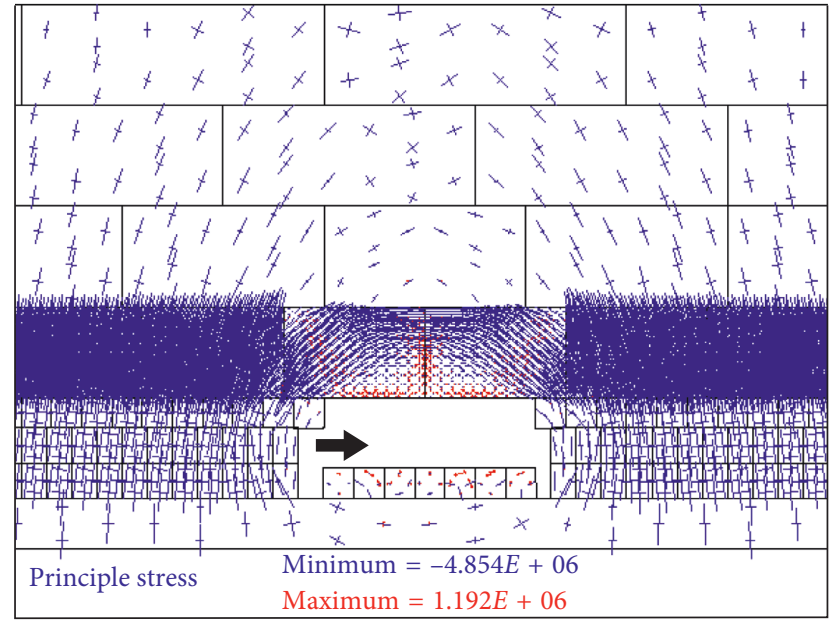

(b)

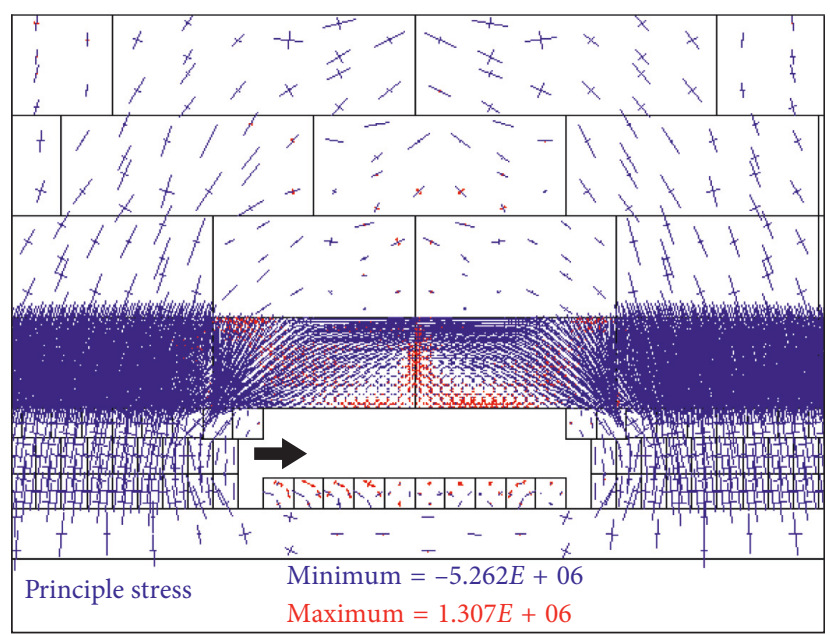

(c)

FIgURE 11: Symmetric pressure-arch structure of two key blocks with different block sizes. (a) $L=10 \mathrm{~m}$. (b) $L=14 \mathrm{~m}$. (c) $L=20 \mathrm{~m}$.
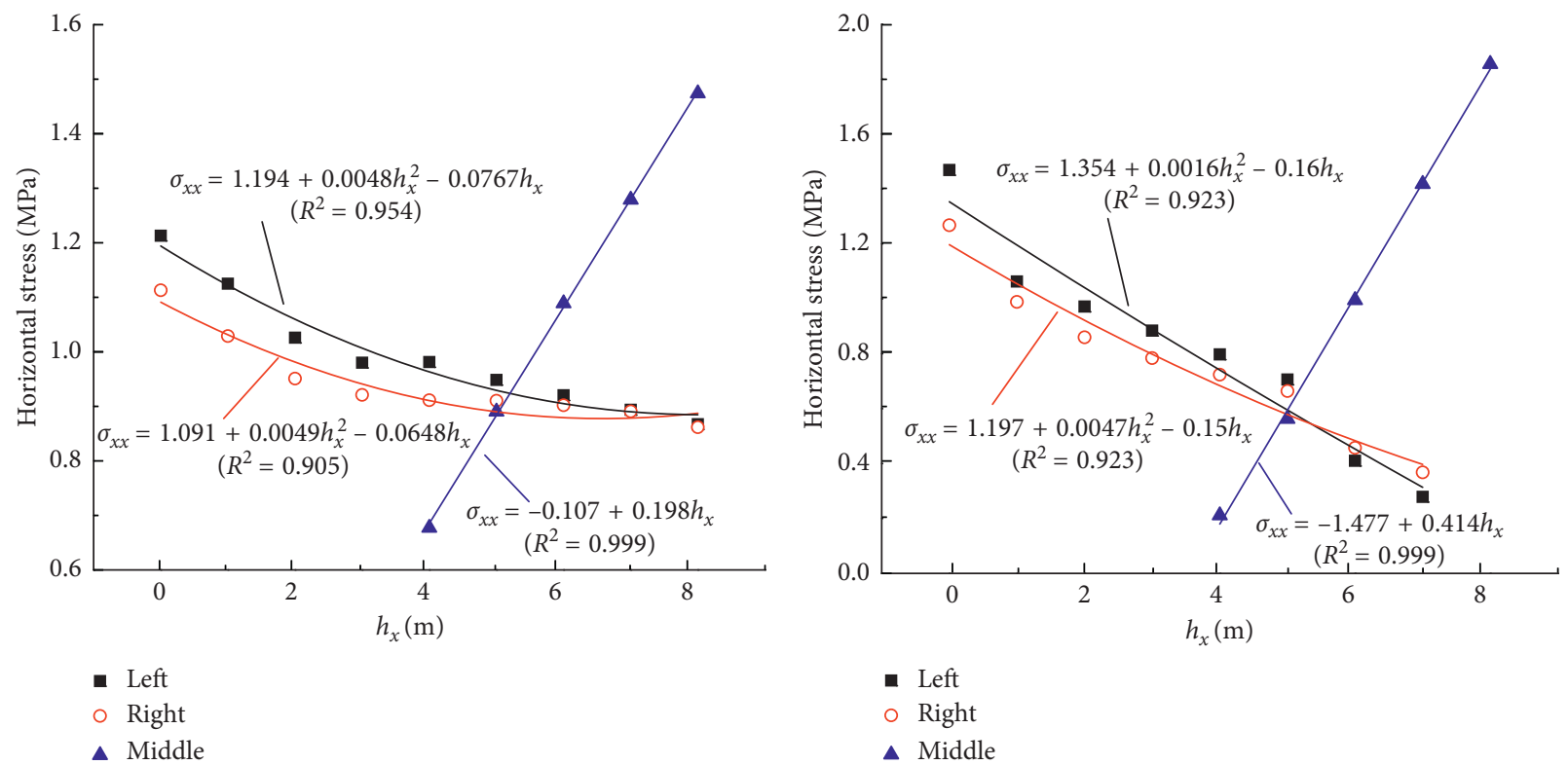

(a)

Figure 12: Continued. 


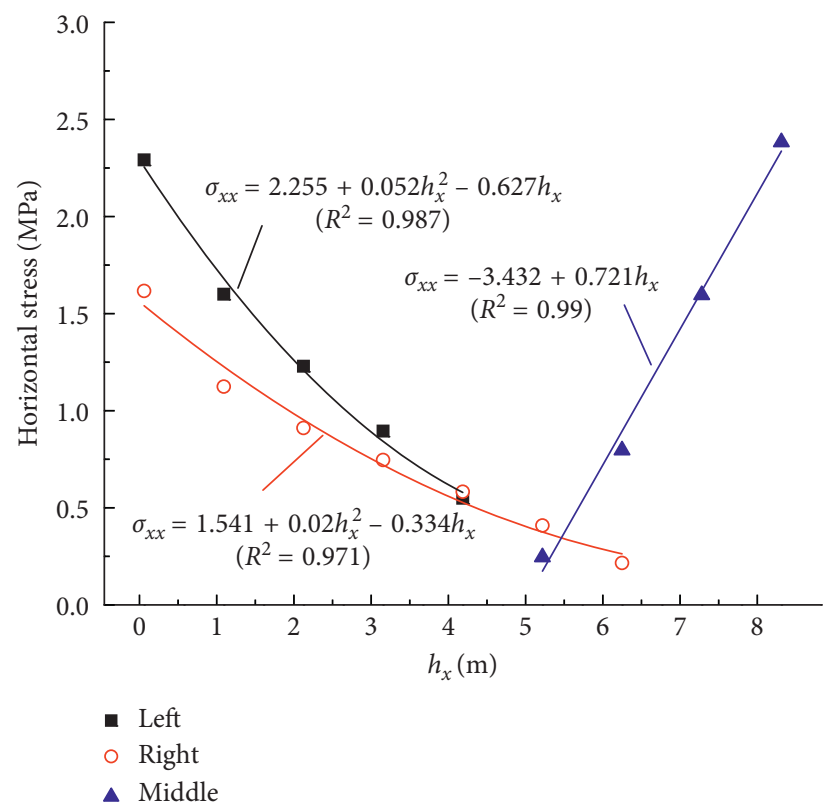

(c)

Figure 12: Distribution law of the horizontal stress in the arch structure. (a) $L=10 \mathrm{~m}$. (b) $L=14 \mathrm{~m}$. (c) $L=20 \mathrm{~m}$.

was formed by the sliding block and the rear blocks. When the semiarch formed again in the main key block over the mining face, the basic roof evolved into a new step pressure-arch structure. Filed observation showed that step subsidence and strong roof weighting were common, which were induced by shallow mining for the large height working face $[4,9]$, and the cyclic evolution of the step pressure-arch structure was the main reason to produce these mining performances. The continuous mining in the large space would weak the arching effect of the compressive stress in the overlying bedrock strata, and the pressure-arch of the bedrock developed upward with the arch abutments moving backward. Moreover, the global pressure-arch structure of the bedrock strata was transformed into the multiple single-layer hinged arch structure and the long periodic roof weighting was produced.

\section{Conclusions}

Taking the fully mechanized mining face with large mining height in the Shendong mining area as the engineering background, theoretical analysis and numerical simulation were used to reveal the pressure-arching effect and the mechanical evolution characteristics of the key blocks under shallow coal mining. The conclusions are listed as follows:

(1) There are three typical structures, such as the symmetrical pressure-arch of two key blocks, the step pressure-arch of multiple key blocks, and the rotative pressure-arch of multiple key blocks during shallow coal mining. The stability of the pressure-arch is affected by the horizontal stress distribution, the roof block is easier to slide as the boundary horizontal stresses display the nonlinear distribution, and the increasing abutment thickness of the pressure-arch can improve the stability of the structure.
(2) In the symmetrical pressure-arch structure, the horizontal stresses show the nonlinear distribution at both abutments and the linear distribution with a higher peak value at the midspan of the arch. The boundary horizontal stresses produce an obvious size effect. With the block length increasing, the peak stress increases and the abutment thickness of the pressure-arch decreases gradually.

(3) In the period of the periodic fracture of the basic roof, the sufficient horizontal stress is necessary to form the rotative pressure-arch of multiple key blocks. The instability and evolution of this structure are the main causes to induce the common step subsidence and strong roof weighting. The long periodic roof weighting is the outcome of the instability of the global pressurearch structure of the multiple layered bedrock.

Due to the complexity of engineering geological conditions and diversity of the roof under shallow coal mining, the bedrock thickness is an key influence factor to the roof weighing; thus, the characteristics of the pressure-arching effect in the roof blocks under different conditions need to be further studied in the future.

\section{Data Availability}

The data used to support the findings of this study are available from the corresponding author upon request.

\section{Disclosure}

The earlier version of the manuscript has been presented as a conference abstract in the 4th ISRM Young Scholars Symposium on Rock Mechanics (according to https://www. onepetro.org/conference-paper/ISRM-YSS-2017-009). 


\section{Conflicts of Interest}

The authors declare that they have no conflicts of interest.

\section{Acknowledgments}

This work was financially supported by the National Natural Science Foundation of China (51774112; 51474188; 51074140), the International Cooperation Project of Henan Science and Technology Department (182102410060), the Doctoral Fund of Henan Polytechnic University (B2015-67), the Research Fund of State and Local Joint Engineering Laboratory for Gas Drainage \& Ground Control of Deep Mines (Henan Polytechnic University) (G201614), and Taihang Scholars Program.

\section{References}

[1] L. Q. Ma, D. S. Zhang, X. Li, G. W. Fan, and Y. F. Zhao, "Technology of groundwater reservoir construction in goafs of shallow coalfields," International Journal of Mining Science and Technology, vol. 19, no. 6, pp. 730-735, 2009.

[2] Y. H. Zhao, S. R. Wang, P. Hagan, and W. B. Guo, "Evolution characteristics of pressure-arch and elastic energy during shallow horizontal coal mining," Tehnicki Vjesnik-Technical Gazette, vol. 25, no. 3, pp. 867-875, 2018.

[3] D. S. Zhang, G. W. Fan, L. Q. Ma, and X. F. Wang, "Aquifer protection during longwall mining of shallow coal seams: a case study in the Shendong Coalfield of China," International Journal of Coal Geology, vol. 86, no. 2-3, pp. 190-196, 2011.

[4] Y. H. Zhao, S. R. Wang, Z. S. Zou, L. L. Ge, and F. Cui, "Instability characteristics of the cracked roof rock beam under shallow mining conditions," International Journal of Mining Science and Technology, vol. 28, no. 3, pp. 437-444, 2018.

[5] J. F. Ju and J. L. Xu, "Structural characteristics of key strata and strata behaviour of a fully mechanized longwall face with $7.0 \mathrm{~m}$ height chocks," International Journal of Rock Mechanics and Mining Sciences, vol. 58, no. 1, pp. 46-54, 2013.

[6] X. S. Liu, Y. L. Tan, and J. G. Ning, "The height of waterconducting fractured zones in longwall mining of shallow coal seams," Geotechnical and Geological Engineering, vol. 33, no. 3, pp. 693-700, 2015.

[7] Y. F. Ren, Y. Ning, and Q. X. Qi, "Physical analogous simulation on the characteristics of overburden breakage at shallow longwall coal face," Journal of China Coal Society, vol. 38, no. 1, pp. 61-66, 2013.

[8] W. Zhang, D. S. Zhang, L. X. Wu, and X. F. Wang, "Numerical simulation on dynamic development features of mining induced fractures in overlying strata during shallow coal seam mining," Electronic Journal of Geotechnical Engineering, vol. 18, pp. 5531-5543, 2013.

[9] Q. X. Huang, B. Dong, and S. S. Chen, "Determination of roof pressure law and support resistance in the mining face with super-large mining height in approximate shallow coal seam," Journal of mining and safety engineering, vol. 33, no. 5, pp. 840-844, 2016.

[10] B. Yu, J. Zhao, T. J. Kuang, and X. B. Meng, "In situ investigations into overburden failures of a super-thick coal seam for longwall top coal caving," International Journal of Rock Mechanics and Mining Sciences, vol. 78, no. 29, pp. 155-162, 2015.

[11] Z. L. Yang, "Stability of nearly horizontal roof strata in shallow seam longwall mining," International Journal of
Rock Mechanics and Mining Sciences, vol. 47, no. 4, pp. 672-677, 2010.

[12] Z. L. Li, L. M. Dou, W. Cai, G. F. Wang, Y. L. Ding, and Y. Kong, "Mechanical analysis of static stress within faultpillars based on a voussoir beam structure," Rock Mechanics and Rock Engineering, vol. 49, no. 3, pp. 1097-1105, 2016.

[13] S. F. Wang, X. B. Li, and D. M. Wang, "Void fraction distribution in overburden disturbed by longwall mining of coal," Environmental Earth Sciences, vol. 75, no. 2, pp. 1-17, 2016.

[14] Y. H. Zhao and X. M. Song, "Stability analysis and numerical simulation of hinged arch structure for fractured beam in super-long mining work face under shallow seam," Rock and Soil Mechanics, vol. 37, no. 1, pp. 203-209, 2016.

[15] D. Bakun-Mazor, Y. H. Hatzor, and W. S. Dershowitz, "Modeling mechanical layering effects on stability of underground openings in jointed sedimentary rocks," International Journal of Rock Mechanics \& Mining Sciences, vol. 46, no. 2, pp. 262-271, 2009.

[16] M. Tsesarsky, "Deformation mechanisms and stability analysis of undermined sedimentary rocks in the shallow subsurface," Engineering Geology, vol. 133, no. 4, pp. 16-29, 2012.

[17] M. Shabanimashcool, R. L. Jing, and C. C. Li, "Discontinuous modelling of stratum cave-in in a longwall coal mine in the Arctic area," Geotechnical and Geological Engineering, vol. 32, no. 5, pp. 1239-1252, 2014.

[18] P. R. Helm, C. T. Davie, and S. Glendinning, "Numerical modelling of shallow abandoned mine working subsidence affecting transport infrastructure," Engineering Geology, vol. 154 , no. 28 , pp. $6-19,2013$. 


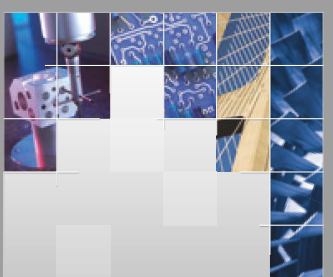

\section{Enfincering}
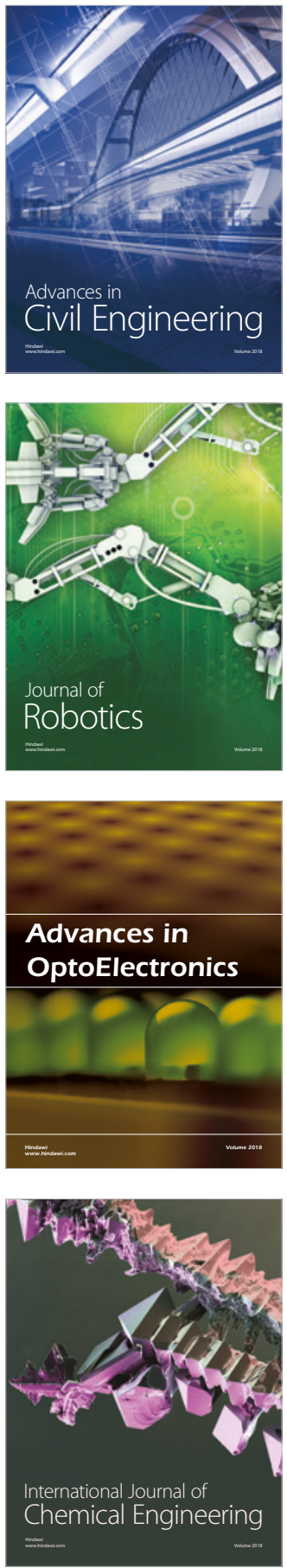

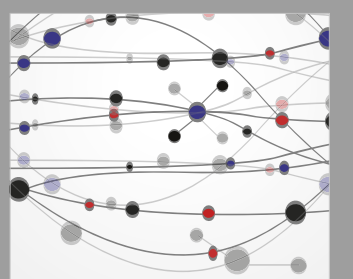

\section{Rotating \\ Machinery}

The Scientific World Journal

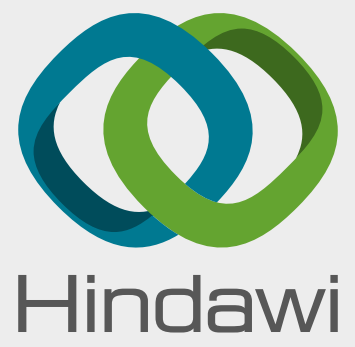

Submit your manuscripts at

www.hindawi.com
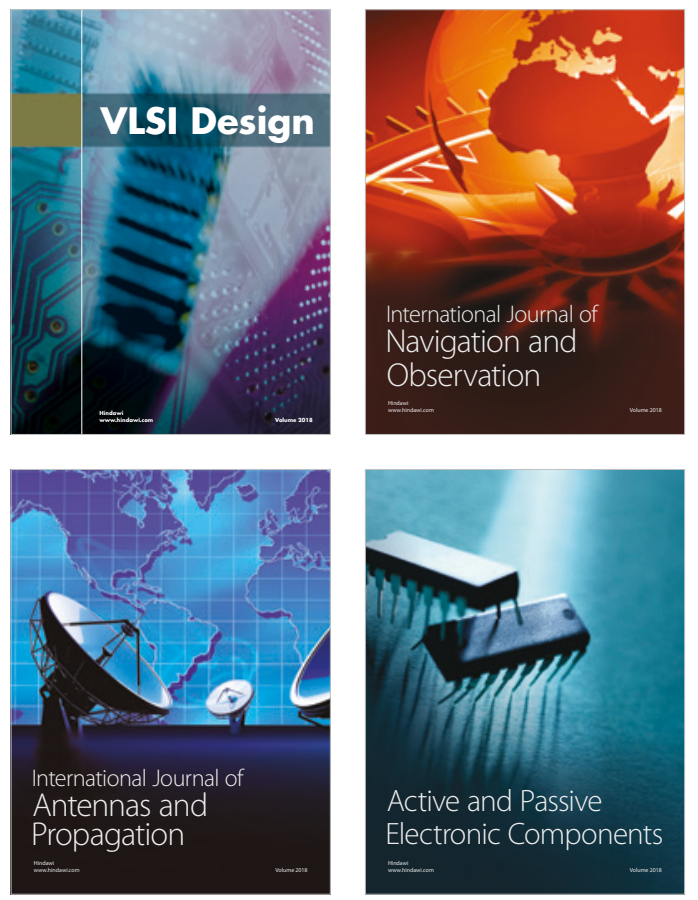
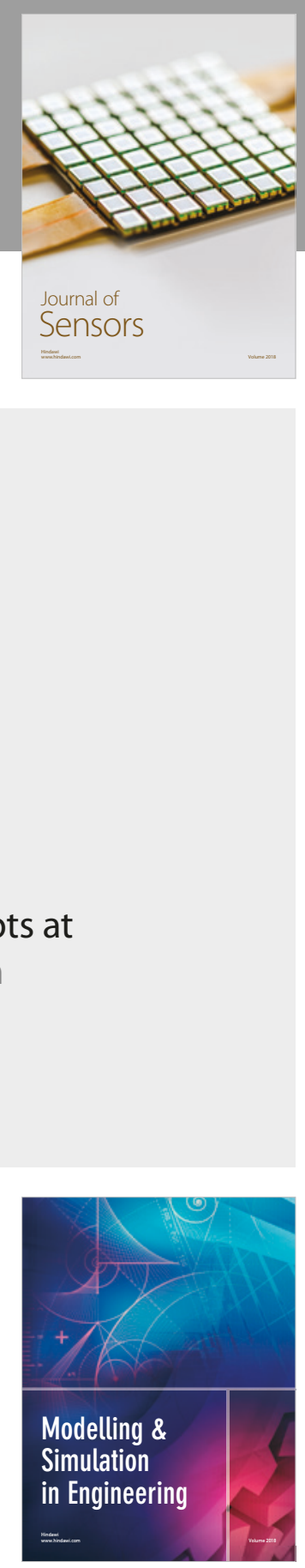

\section{Advances \\ Multimedia}
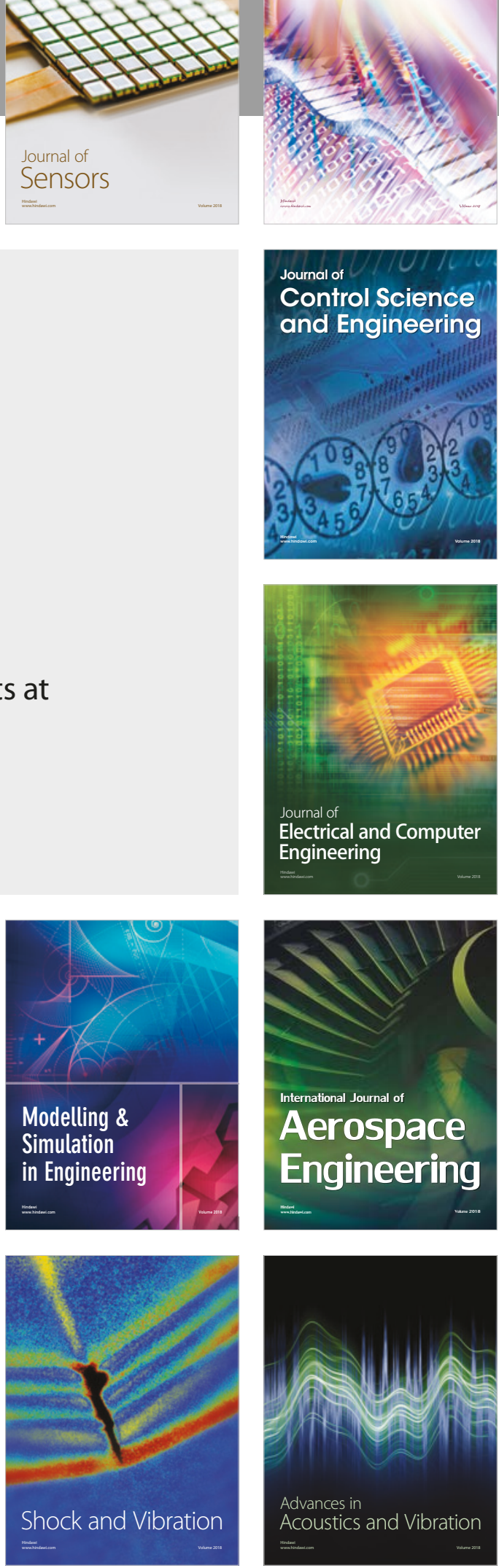